\title{
TEOR DE CLOROFILA E ÍNDICE SPAD NO ABACAXIZEIRO cv. VITÓRIA EM FUNÇÃO DA ADUBAÇÃO NITROGENADA ${ }^{1}$
}

\author{
FRANCISCO DE ASSIS PEREIRA LEONARDO², WALTER ESFRAIN PEREIRA ${ }^{3}$ \\ SILVANDA DE MELO SILVA ${ }^{4}$, JANDIRA PEREIRA DA COSTA ${ }^{5}$
}

RESUMO -Tendo em vista a demanda do mercado por novas variedades e a necessidade de melhoria no manejo nutricional do abacaxizeiro, realizou-se este experimento com objetivo de avaliar o teor de clorofila e o índice SPAD no abacaxizeiro 'Vitória' em função da adubação nitrogenada com ureia e cama de frango. Para o efeito, foi instalado um experimento no delineamento em blocos casualizados, com quatro repetições. Os tratamentos consistiram em cinco doses de N, em duas fontes, orgânica (cama de frango) e mineral (ureia), totalizando nove combinações geradas através da matriz Composto Central de Box: $\mathrm{T}_{1}, 44$ e 2,$91 ; \mathrm{T}_{2}, 152$ e $0 ; \mathrm{T}_{3}, 0$ e $10 ; \mathrm{T}_{4}, 44$ e 17,$1 ; \mathrm{T}_{5}, 260$ e 2,$91 ; \mathrm{T}_{6}, 152$ e $10 ; \mathrm{T}_{7}, 152$ e $20 ; \mathrm{T}_{8}, 304$ e $10 ;$ e $\mathrm{T}_{9}$, 260 e 17,1 $\mathrm{g} \mathrm{planta}^{-1}$. Foram avaliados o índice SPAD, o teor de clorofila na folha e o teor de $\mathrm{N}$ na folha $\mathrm{D}$. Para o teor relativo de clorofila (SPAD), estimou-se o máximo valor com as doses de $16,37 \mathrm{~g} \mathrm{planta}^{-1}$ de ureia e 200,69 g planta $^{-1}$ de cama de frango. Para o teor de clorofila na folha D, obteve-se o valor máximo estimado com 19,4 $\mathrm{g}_{\text {planta }}{ }^{-1}$ de ureia. O índice SPAD possui correlação positiva com o teor de clorofila e com o teor de $\mathrm{N}$ na folha.

Termos de Indexação: Ananas comosus; SPAD; ureia; cama de frango.

\section{CONTENT OF CHLOROPHYLL AND SPAD INDEX IN PINEAPPLE CV. VITÓRIA IN FUNCTION OF ORGANIC-MINERAL FERTILIZATION}

\begin{abstract}
Given the need for utilization of new varieties and improving the nutritional aspects of pineapple, it was conducted this experiment to evaluate the chlorophyll content and SPAD index in pineapple 'Vitória' in function of nitrogen (N) fertilization with urea and poultry litter . For this purpose, an experiment was conducted in randomized block design with four replications. The treatments consisted of five $\mathrm{N}$ doses from two sources, organic (poultry litter) and mineral (urea), resulting in nine combinations generated from Central Composite Box Design: $\mathrm{T}_{1}, 44$ and 2.91; $\mathrm{T}_{2}, 152$ and $0 ; \mathrm{T}_{3}, 0$ and 10; $\mathrm{T}_{4}, 44$ and 17.1; $\mathrm{T}_{5}, 2.91$ and 260; $\mathrm{T}_{6}, 10$ and 152; $\mathrm{T}_{7}, 152$ and 20; $\mathrm{T}_{8}, 304$ and 10 and $\mathrm{T}_{9}, 260$ and $17.1 \mathrm{~g} \mathrm{plant}^{-1}$. The SPAD index, the content of chlorophyll in the leaf and the $\mathrm{N}$ content in the D leaf were evaluated. For the relative chlorophyll content (SPAD) has been estimated the maximum value at doses of $16.37 \mathrm{~g} \mathrm{plant}^{-1}$ of urea and $200.69 \mathrm{~g}$ plant $^{-1}$ of poultry litter. For the content of chlorophyll the maximum value has been estimated with $19.4 \mathrm{~g}$ plant $^{-1}$ of urea. The SPAD index has positive correlation with chlorophyll and $\mathrm{N}$ concentration in the leaf.

Index terms: Ananas comosus; SPAD; urea; poultry litter.
\end{abstract}

\footnotetext{
${ }^{1}$ (Trabalho 228-12). Recebido em: 27-08-2012. Aceito para publicação em: 01-04-2013.

${ }^{2}$ Doutorando em Agronomia, Programa de Pós- Graduação em Agronomia CCA-UFPB. . End: CCA-UFPB, Campus II, Areia-PB, CEP: 58397-000 email:fap_leonardo@hotmail.com

${ }^{3}$ Professor Dr. associado do DCFS-CCA-UFPB, bolsista de produtividade do CNPq. End: CCA-UFPB, Campus II, Areia-PB, CEP: 58397-000 Email: wep@cca.ufpb.br

${ }^{4}$ Professora Dra. associada do DCFS-CCA-UFPB, bolsista de produtividade do CNPq. . End: CCA-UFPB, Campus II, Areia-PB, CEP: 58397-000 email:silvasil@cca.ufpb.br.

${ }_{5}^{5}$ Doutoranda em Agronomia, Programa de Pós- Graduação em Agronomia CCA-UFPB. . End: CCA-UFPB, Campus II, Areia-PB, CEP: 58397-000 Email: jandagro@hotmail.com
} 


\section{INTRODUÇÃO}

A cultivar Vitória, por apresentar características agronômicas semelhantes ou superiores em relação às cvs. Pérola e Smooth Cayenne, usadas como referência, além de apresentar alta resistência à principal doença da cultura, a fusariose (MELETTI, 2011), apresentase como alternativa para aumentar o rendimento da cultura, já que a principal causa de perdas é provocada por esta doença (VENTURA et al., 2009). No entanto, para se obter melhorias no rendimento do abacaxizeiro, é necessário conhecer os aspectos nutricionais para atendimento de suas exigências.

O nitrogênio é elemento essencial para as plantas por fazer parte de uma série de compostos indispensáveis ao seu desenvolvimento, como das moléculas de clorofila, das bases nitrogenadas dos nucleotídeos, dos aminoácidos, proteínas (dentre as quais a enzima ribulose 1,5-bifosfato carboxilase oxigenase - Rubisco, catalisadora da redução fotossintética do $\mathrm{CO}_{2}$ ) e de vários compostos do metabolismo secundário. Para fazer parte destas substâncias, o nitrogênio deve ser absorvido da rizosfera pelas raízes, onde deve estar disponibilizado normalmente na forma de $\mathrm{N}^{-} \mathrm{NH}_{4}^{+}$ ou N-NO ${ }_{3}^{-}$(TAIZ; ZEIGER, 2008).

Autilização de matéria orgânica em conjunto com a adubação mineral, além de aumentar sua eficiência, resulta em diversos benefícios, nos aspectos físicos, químicos e biológicos do solo, permitindo a melhoria na estrutura física para o desenvolvimento da planta, aumento na capacidade de retenção de água e nutrientes, devido à maior diversidade e atividade dos microrganismos do solo (SINGH et al., 2010).

O uso do clorofilômetro permite estimar, de forma rápida e barata, a concentração de $\mathrm{N}$ nas folhas das plantas e, com isto, pode contribuir para a diminuição da sub ou superutilização de fertilizantes nitrogenados (SANT'ANA et al., 2010). As leituras instantâneas de maneira não destrutiva de folhas, proporcionadas pelo clorofilômetro, apresentam-se como alternativa de indicação do teor de clorofila presente na folha da planta (KLOOSTER et al., 2012). O teor de clorofila correlaciona-se com a concentração de $\mathrm{N}$ na planta e, também, com a produtividade das culturas (SILVA et al.,2012b). Em algumas frutíferas, como citros (SOUZA et al., 2011) e nogueira-pecã (HARDIN et al., 2012), o uso do índice SPAD tem-se mostrado adequado para auxiliar no manejo na adubação nitrogenada. Em abacaxizeiro, não existe informação disponível na literatura científica

Devido à facilidade para determinar o índice SPAD pelos produtores, com o propósito de monitorar o estado nutricional do abacaxizeiro, realizou-se este experimento, objetivando-se avaliar o índice SPAD e o teor de clorofila no abacaxizeiro 'Vitória' adubado com doses de nitrogênio a partir de duas fontes: mineral, na forma de ureia, e orgânica, na forma de cama de frango.

\section{MATERIAL E MÉTODOS}

A pesquisa foi realizada em condições de campo, na Fazenda Quandu Itapororoca, localizada a aproximadamente $11 \mathrm{~km}$ da sede do município de Itapororoca-PB. O clima prevalecente na região é do tipo As', quente e úmido com chuvas de outonoinverno, período de estiagem de cinco a seis meses, temperaturas médias variando entre 22 e $26{ }^{\circ} \mathrm{C}$ e precipitação pluviométrica anual de $1.500 \mathrm{~mm}$. Os dados pluviométricos foram coletados na cidade de Araçagi-PB, localizada a aproximadamente $15 \mathrm{~km}$ da área experimental (Figura 1).

O delineamento experimental utilizado foi o de blocos casualizados, com quatro repetições, os tratamentos consistiram em cinco doses de $\mathrm{N}$, em duas fontes, orgânica (cama de frango) e mineral (ureia), totalizando nove combinações geradas através da matriz Composto Central de Box (Tabela 1). As doses de $\mathrm{N}$ foram definidas com base nas recomendações de $\mathrm{N}$ para o abacaxizeiro, conforme Silva et al. (2009).

O solo apresenta textura areia franca e as seguintes características químicas: $\mathrm{pH}=5,5 ; \mathrm{P}$ $\left(\right.$ melich1) $=3,3 \mathrm{mg} \mathrm{dm}-3 ; \mathrm{K}=74,28 \mathrm{mg} \mathrm{dm}^{-3} ; \mathrm{Na}+=$ $0,2 \mathrm{cmolc} \mathrm{dm}^{-3} ; \mathrm{H}+\mathrm{Al}=11,22 \mathrm{cmol}_{\mathrm{c}} \mathrm{dm}^{-3} ; \mathrm{Al}=0,2$ cmol dm $\mathrm{dm}^{-3} ; \mathrm{Ca}=3,05 \mathrm{cmol} \mathrm{dm}^{-3} ; \mathrm{Mg}=1,25 \mathrm{cmol}$ $\mathrm{dm}^{-3} ; \mathrm{SB}=4,75 \mathrm{cmol}_{\mathrm{c}} \mathrm{dm}^{-3} ; \mathrm{CTC}=15,97 \mathrm{cmol}^{\mathrm{c}}$ $\mathrm{dm}^{-3} ; \mathrm{V}=29,74 \% ; \mathrm{m}=4,04 \% ;$ M.O. $=8,65 \mathrm{~g} \mathrm{~kg}^{-1}$. A composição da cama de frango utilizada no experimento foi: M.O. $=602,2 \mathrm{~g} \mathrm{~kg}^{-1} \mathrm{C}=349,2 \mathrm{~g}$ $\mathrm{kg}^{-1} ; \mathrm{N}=34,5 \mathrm{~g} \mathrm{~kg}^{-1} ; \mathrm{P}=13,7 \mathrm{~g} \mathrm{~kg}^{-1} ; \mathrm{K}=46,5 \mathrm{~g} \mathrm{~kg}^{-1}$; $\mathrm{S}=0,3454 \mathrm{~g} \mathrm{~kg}^{-1} ; \mathrm{Mg}=5,5 \mathrm{~g} \mathrm{~kg}^{-1} ;$ relação $\mathrm{C} / \mathrm{N}=10 / 1$; umidade $=38,7 \% \mathrm{pH}: 7,25$.

O preparo do solo foi feito através da limpeza da área, gradagem e incorporação dos restos culturais do ciclo anterior. Na adubação de plantio, foi aplicado fósforo $154 \mathrm{~kg}$ de $\mathrm{P}_{2} \mathrm{O}_{5}$ ha $^{-1}$. O potássio apresentou teores adequados $\left(74,28 \mathrm{mg} \mathrm{dm}^{-3}\right) \mathrm{r}$, não sendo necessária a adição de adubos potássicos. A adubação em cobertura foi parcelada em três aplicações, sendo a primeira aos dois meses após o transplantio das mudas, em abril de 2010 , composta por $50 \%$ das doses de ureia e $50 \%$ das doses de cama de frango; 
a segunda, aos seis meses após o transplantio, em agosto de 2010, composta pelos 50\% restantes das doses de cama de frango, e a terceira aos onze meses após o transplantio das mudas, em janeiro de 2011, composta pelos $50 \%$ restantes das doses de ureia.

O plantio foi realizado em fevereiro de 2010 , com mudas de abacaxi da cultivar Vitória, produzidas por cultivo in vitro. As mudas foram plantadas em leirões, no sistema de fileiras duplas, no espaçamento de $0,9 \times 0,40 \times 0,40 \mathrm{~m}$, resultando numa densidade de 38.400 plantas ha $^{-1}$.

$\mathrm{Na}$ condução do experimento, foram realizadas as práticas culturais usuais para a cultura, visando a garantir boas condições de limpeza e de sanidade das plantas. O controle de plantas daninhas foi efetuado com o uso do herbicida Diuron, em pósemergência, e através de capinas manuais, com o auxílio de enxadas. A irrigação foi feita nos períodos de ausência de precipitação pelo, método de aspersão convencional.

Os dados do teor relativo de clorofila (SPAD) foram determinados mediante duas leituras com clorofilômetro, modelo Minolta SPAD-502, na parte mediana da folha $\mathrm{D}$, em 10 folhas por parcela. As leituras do índice SPAD e as folhas foram coletadas em março de 2011, dois meses após a aplicação da última adubação. Para clorofila total, logo após a realização da leitura SPAD, foram coletadas três folhas por parcela e levadas para o Laboratório de Pós-colheita do Centro de Ciências Agrárias da UFPB, retirada uma porção no terço médio superior de cada folha e determinada pelo método Arnon (1949). O restante das folhas utilizadas para o teor de clorofila foi lavado com detergente neutro e água destilada, e em seguida, levadas para estufa de circulação de ar para secagem, moídas em moinho tipo Willey e determinado o teor de $\mathrm{N}$, segundo metodologia de Tedesco, et al. (1995). De acordo com Malavolta et al. (1997), o verão é a melhor época de coleta da folha ' $\mathrm{D}$ ' diagnóstica do abacaxizeiro .

Os dados obtidos foram submetidos a análises de variância e análises de regressão polinomial, utilizando-se do software SAS 9.3 (2011).

\section{RESULTADOS E DISCUSSÃO}

Para o índice SPAD, houve efeito significativo para as duas fontes de N. Através da derivada da equação, obteve-se o máximo teor relativo de clorofila com as doses de $16,37 \mathrm{~g}_{\text {planta }}{ }^{-1}$ de ureia e 200,69 g planta $^{-1}$ de cama de frango, proporcionando um índice máximo de 55,26 e 44,68 para ureia e cama de frango, respectivamente (Figura 2).

Diversos autores encontraram efeitos de doses de $\mathrm{N}$ no índice SPAD, tendo um ajuste linear na laranjeira (SOUZA et al., 2011) e no citrumeleiro (VALE; PRADO, 2009) e ajuste ao modelo exponencial (TORRES NETO et al., 2002) no mamoeiro.

Verificou-se efeito significativo do adubo mineral aplicado na forma de ureia, sobre o teor de clorofila. Utilizando-se da derivada da equação apresentada na Figura 3, obteve-se o valor máximo de $0,25 \mathrm{mg} \mathrm{g}^{-1}$ de clorofila total na dose de $19,4 \mathrm{~g}$ planta $^{-1}$ de ureia. Vieira et al. (2010), em mudas de abacaxizeiro cv Pérola, revelaram diferenças significativas de teores de clorofilas $a, b$ e total, em função de doses de sulfato de amônio.

A influência da adubação nitrogenada sobre o teor de clorofila deve-se ao fato de, com a deficiência de $\mathrm{N}$ no solo, a planta degrada as moléculas de clorofila, para translocar o $\mathrm{N}$ para as regiões de crescimento ativo (FURLANI JUNIOR et al., 1996).

O teor de $\mathrm{N}$ na folha do abacaxizeiro 'Vitória' foi influenciado pelas doses de ureia $\mathrm{O}$ máximo valor estimado do teor de $\mathrm{N}$ foi de $12,62 \mathrm{~g} \mathrm{~kg}^{-1}$ (Figura 4). O N é um dos elementos utilizados na síntese de clorofila. O teor de clorofila correlacionase positivamente com o teor de $\mathrm{N}$ na planta e com o rendimento das culturas. Esta relação é atribuída, principalmente, ao fato de que 50 a $70 \%$ do $\mathrm{N}$ total das folhas façam parte de enzimas que estão associadas aos cloroplastos (SINGH et al., 2010; REINBOTHE et al., 2010).

Os teores estão abaixo da faixa entre $15 \mathrm{e}$ $17 \mathrm{~g} \mathrm{~kg}^{-1}$ considerada adequada por Malézieux e Bartholomew (2003). Entretanto, as concentrações de $\mathrm{N}$ para todos os tratamentos, aos 13 meses após o transplantio, estiveram acima do valor limítrofe considerado por Malézieux e Bartholomew (2003), de $8,7 \mathrm{~g} \mathrm{~kg}^{-1}$, para o crescimento de novos tecidos.

Utilizando mudas meristemáticas da cultivar Vitória, Silva et al. (2012a) observaram teores de $\mathrm{N}$ abaixo dos apresentados neste experimento, com média de 7,53 $\mathrm{g} \mathrm{kg}^{-1}$ aos 14 meses após o plantio. Essa diferença ocorreu, possivelmente, devido a variações de temperatura e precipitação, ocasionando perdas por volatilização e lixiviação, respectivamente. À época de aplicação, o parcelamento e a forma de aplicação do $\mathrm{N}$ também podem ter influenciado na obtenção de valores baixos de $\mathrm{N}$.

$\mathrm{O}$ índice SPAD possui correlação direta com o teor de clorofila $(0,91)$ e com o teor de $\mathrm{N}$ na folha $(0,87)$, verificando-se correlação positiva entre ambas as variáveis. O teor de clorofila na folha $\mathrm{D}$ aumenta $0,0061 \mathrm{mg} \mathrm{g}^{-1}$ à medida que o índice 
SPAD aumenta uma unidade e o teor de $\mathrm{N}$ aumenta $0,165 \mathrm{~g} \mathrm{~kg}^{-1}$ de $\mathrm{N}$ na folha com a elevação de uma unidade do índice SPAD (Figuras 3 e 4). De forma semelhante, Hardin et al. (2012), em nogueirapecã, encontraram correlação positiva do índice SPAD com os teores de clorofila total.

A correlação verificada entre o índice SPAD e teor de clorofila total evidencia que as leituras efetuadas com clorofilômetro estimam, adequadamente, o grau de esverdeamento das folhas de abacaxizeiro cv. Vitória. Portanto, as leituras efetuadas pelo equipamento podem substituir, com precisão adequada, as determinações tradicionais do teor de clorofila para a cultura do abacaxizeiro. Em outras espécies, a correlação entre $\mathrm{N}$ e índice SPAD foi encontrada por Coelho et al. (2012) e Errecart et al. (2012).

De forma semelhante, a elevada correlação entre o índice SPAD e o teor foliar de $\mathrm{N}$ indica a possibilidade do uso do clorofilômetro para avaliar de forma rápida o estado nutricional do nitrogênio em abacaxizeiro, de forma semelhante ao praticado com outras frutíferas.

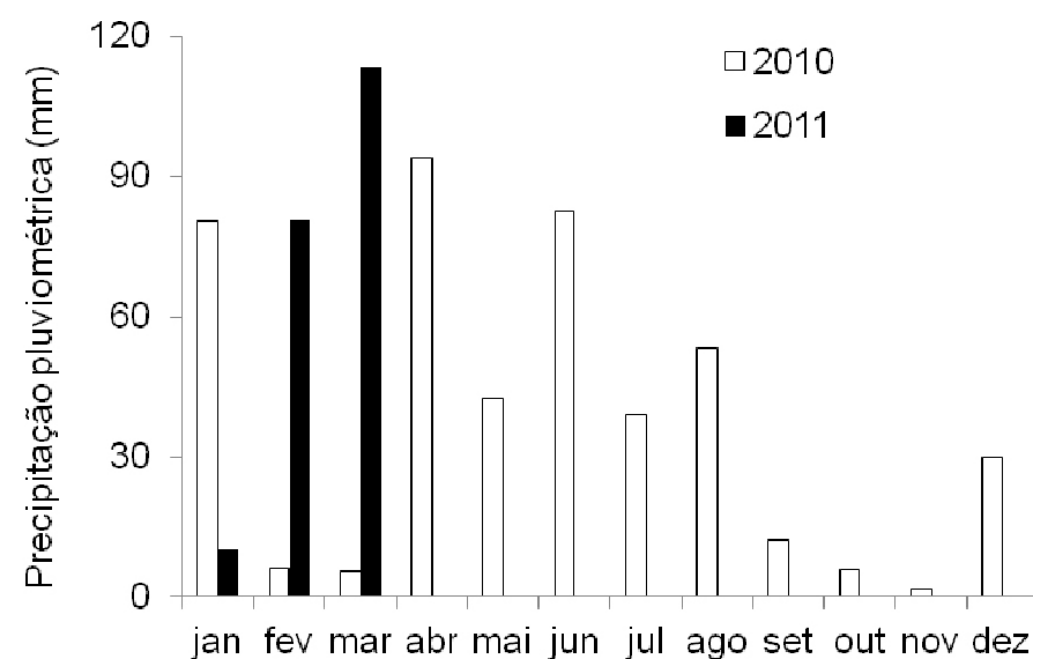

FIGURA 1- Precipitação pluviométrica no município de Araçagí, PB, no período do experimento.

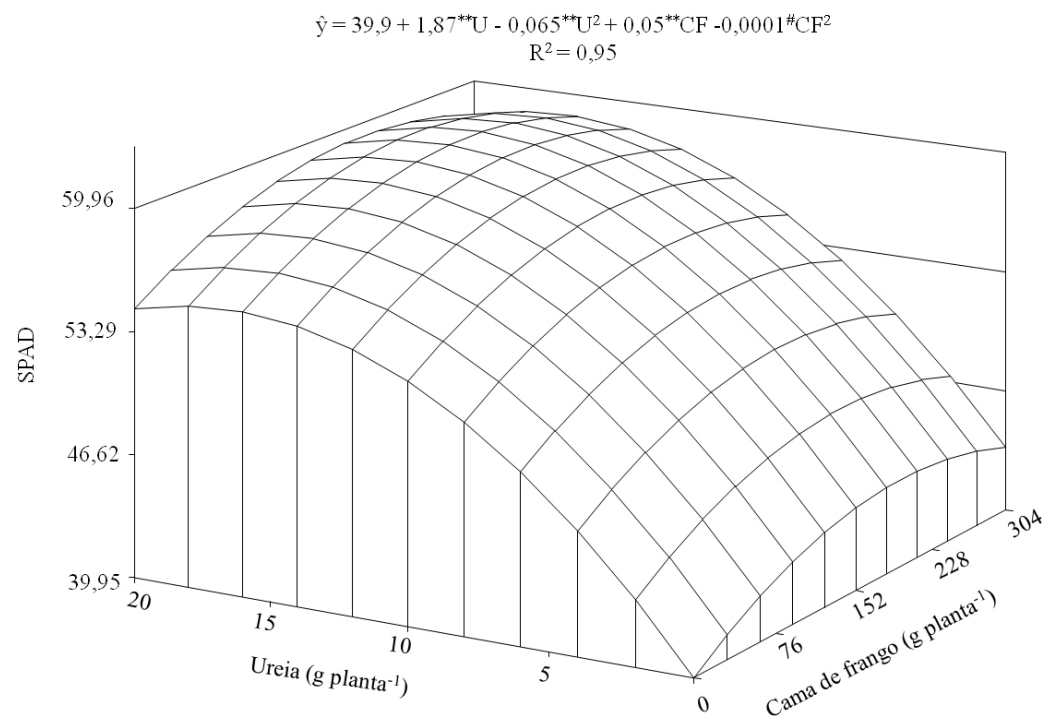

*, ** e \#: significativo a 5, 1 e $10 \%$ de probabilidade, respectivamente.

FIGURA 2- Teor relativo de clorofila 'SPAD' em abacaxi 'Vitória', em função de doses de ureia e cama de frango, Itapororoca, PB, 2011. 

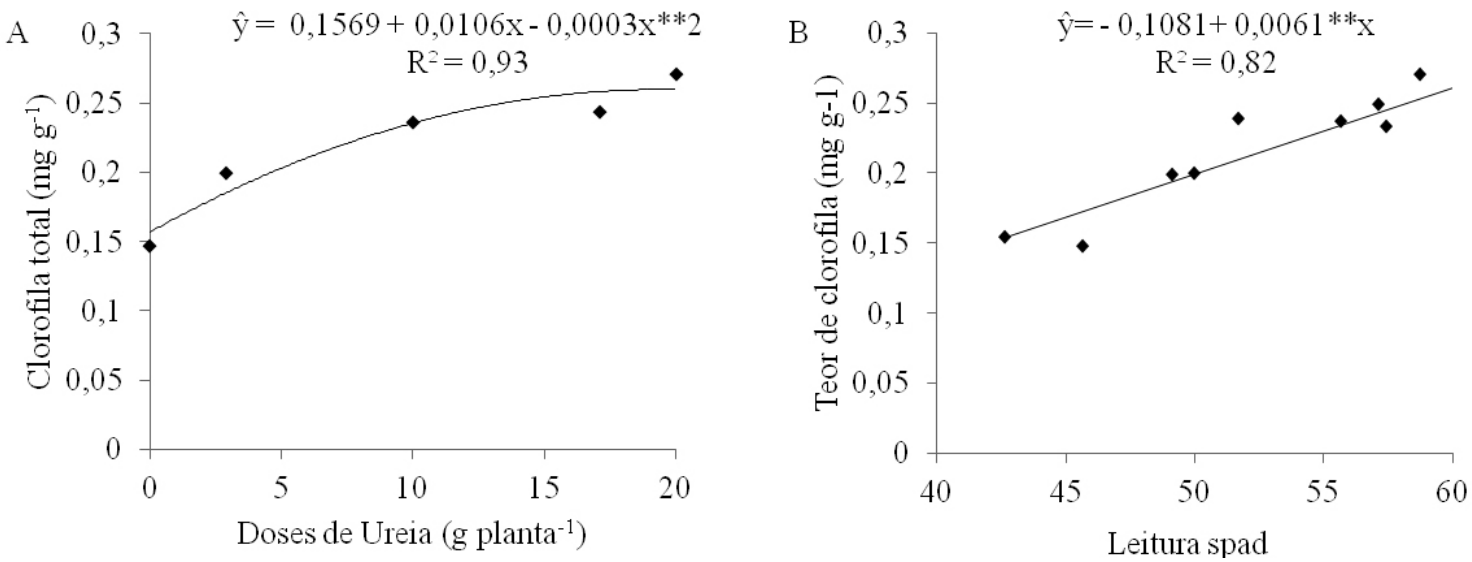

FIGURA 3 - Clorofila total aos 13 meses após o plantio, em função de doses de ureia (A), e correlação entre teor de clorofila e índice SPAD (B) no abacaxizeiro cv. Vitória, Itapororoca-PB, 2011.

**: significativo a $1 \%$ de probabilidade.
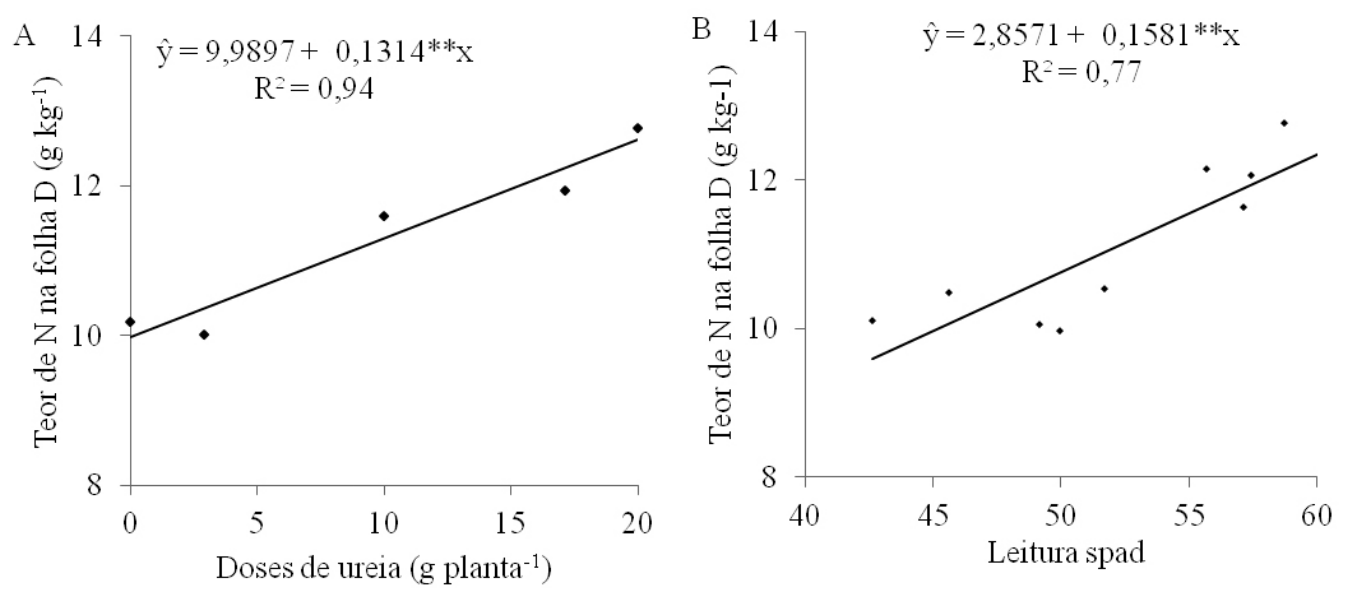

FIGURA 4-Teor de $\mathrm{N}$ na folha $\mathrm{D}$ aos 13 meses após o plantio (A) e correlação entre teor de $\mathrm{N}$ e índice SPAD (B) no abacaxizeiro cv. Vitória, Itapororoca-PB, 2011.

**: significativo a $1 \%$ de probabilidade.

\section{CONCLUSÕES}

1- A cama de frango e a ureia aumentam o índice SPAD nas folhas D do abacaxizeiro 'Vitoria',

2- A adubação com ureia aumenta o teor de clorofila e de $\mathrm{N}$ na folha $\mathrm{D}$.

3- O índice SPAD correlaciona-se positivamente com o teor de clorofila e o teor foliar de $\mathrm{N}$.

\section{AGRADECIMENTOS}

À Capes, pela concessão da bolsa; ao BNB, pelo apoio financeiro. 


\section{REFERÊNCIAS}

COELHO, F S.; FONTES, P C R.; FINGER, F L; CECON, P R. Avaliação do estado nutricional do nitrogênio em batateira por meio de polifenóis e clorofila na folha. Pesquisa Agropecuária Brasileira, Brasília, v.47 n.4. p. 584-592, 2012.

ERRECART, PM.; AGNUSDEI, MG.; LATTANZI, FA.; MARINO, MA. Leaf nitrogen concentration and chlorophyll meter readings as predictors of tall fescue nitrogen nutrition status. Field Crops Research, Amsterdam, v.129, p.46-58, 2012.

FURLANI JÚNIOR, E., NAKAGAWA, J., BULHÕES, L.J., MOREIRA, J.A.A., GRASSI FILHO, H. Correlation between chlorophyll readings and levels of nitrogen applied in bean. Bragantia, Campinas, v.55, p.171-175, 1996.

HARDIN, J. A.; SMITH, M. W.; WECKLER, P. R.; CHEARY, B. S. In Situ Measurement of Pecan Leaf Nitrogen Concentration using a Chlorophyll Meter and Vis-near Infrared Multispectral Camera. Hortscience, Alexandria, v.47, n.7, p.955-960, 2012.

KLOOSTER, WS.; CREGG, BM.; FERNANDEZ, RT.; NZOKOU, P. Growth and physiology of deciduous shade trees in response to controlledrelease fertilizer. Scientia Horticulturae, Amsterdam, v.35, p.71-79, 2012.

MALAVOLTA, E.; VITTI, G.C.; OLIVEIRA, S.S. Avaliação do estado nutricional das plantas: princípios e aplicações. 2.ed. Piracicaba: Potafos, 1997. 319p.

MALÉZIEUX, E.; BARTHOLOMEW, D.P. Plant nutrition. In: BARTHOLOMEW, D.P.; PAUL, R.E.; ROHRBACH, K.G. (Ed.). The pineapple: botany, production and uses. Honolulu: CAB, 2003. p.143165.

MELETTI, L.M., Avanços na fruticultura tropical no Brasil. Revista Brasileira de Fruticultura, Jaboticabal, v. 33, n.1 - edição especial, p. 73 - 76, 2011.

REINBOTHE, C.; BAKKOURI, M.; BUHR, F.; MURAKI, N.; NOMATA, J.; KURISU, G.; FUJITA, Y. E REINBOTHE, S. Chlorophyll biosynthesis: spotlight on protochlorophyllide reduction. Trends in Plant Science, Oxford, v.15, n.11, p.614-624, 2010.
SANT'ANA, E V P.; SANTOS, A B.; SILVEIRA, P $M$. Adubação nitrogenada na produtividade, leitura spad e teor de nitrogênio em folhas de feijoeiro. Pesquisa Agropecuária Tropical, Goiânia, v. 40, n. 4, p. 491-496, 2010.

SAS INSTITUTE. Statistical analysis system: release 9.3. Cary: Statistical Analysis System Institute, 2011 .

SILVA, A.L.P.; SILVA, A.P.; SOUZA, A.P.; SANTOS, D.; SILVA, S.M., SILVA, V.B.. Resposta do abacaxizeiro 'Vitória' a doses de nitrogênio em solos de tabuleiros costeiros da Paraíba. Revista Brasileira de Ciência do Solo, Viçoisa, MG, v.36, n.2, p. 447-456, 2012a.

SILVA, A.P.; ALVAREZ V.,V.H.; SOUZA,A.P.; NEVES, J.C.L.; NOVAIS, R.F.; DANTAS, J.P. Sistema de recomendação de fertilizantes e corretivos para a cultura do abacaxi - FERTCALC-Abacaxi. Revista Brasileira de Ciência do Solo, Viçosa, MG, v.33, p.1269-1280, 2009.

SILVA, MAG.; MANNIGEL, A R.; MUNIZ, A S.; PORTO, S M A.; MARCHETTI, M E.; NOLLA, A.; BERTANI, R M A. Ammonium sulphate on maize crops under no tillage. Bragantia, Campinas, v.71, n.1, p. 90-97, 2012 b.

SINGH, V.; SINGH, B.; SINGH, Y.; THIND, H. S. E GUPTA, R. K. Need based nitrogen management using the chlorophyll meter and leaf colour chart in rice and wheat in South Asia: a review. Nutrient Cycling Agroecosyst, Dordrecht, v.88, p.361-380, 2010.

SOUZA, T. R.; SALOMÃO, L. C.; ANDRADE, T. F.; BÔAS, R. L. V.; QUAGGIO, J. A. Medida indireta da clorofila e sua relação com o manejo da adubação nitrogenada em plantas cítricas fertirrigadas. Revista Brasileira de Fruticultura, Jaboticabal, v. 33, n. 3 , p. 993-1003, 2011.

TAIZ, L.; ZEIGER, E. Fisiologia vegetal. 3. ed. Porto Alegre: Artmed, 2008. 719p.

TEDESCO, M.J.; GIANELLO, C.; BISSANI, C.A.; BOHNEM, H.; VOLKWEISS, S.J. Análise de solo, plantas e outros materiais. Porto Alegre: UFRGS, 1995. 174p. (Boletim Técnico). 
TORRESNETO,A.CAMPOSTRINI, E.; OLIVEIRA, JG; YAMANISHI, O.K. Portable chlorophyll meter for the quantification of photosynthetic pigments, nitrogen and the possible use for assessment of the photochemical process in Carica papaya L. Brazilian Journal of Plant Physiology, Piracicaba, v. 14, n. 3, p. 203-210, 2002.

VALE, D. W.; PRADO, R. M. Adubação com NPK e o estado nutricional de 'citrumelo' por medida indireta de clorofila. Revista Ciência Agronômica, Fortaleza, v.40, n.02, p. 266-271, 2009.
VENTURA, J. A.; COSTA, H. e CAETANO, L. C. S.. Abacaxi 'vitória': uma cultivar resistente à fusariose. Revista Brasileira de Fruticultura, Jaboticabal, v.31, n.4, p.1-2, 2009.

VIEIRA, D. A. P.; PORTES, T. A.; STACCIARINISERAPHIN, E.; TEIXEIRA, J. B. Fluorescência e teores de clorofilas em abacaxizeiro cv. Pérola submetido a diferentes concentrações de sulfato de amônio. Jaboticabal - SP. Revista Brasileira de Fruticultura, Jaboticabal, v. 32, n. 2, p. 360-368, 2010 . 